\title{
Light-Evoked Oxygen Responses in the Isolated Toad Retina
}

\author{
LAURA M. HAUGH-SCHEIDT ${ }^{a *}$, EDWIN R. GRIFF AND ROBERT A. LINSENMEIER ${ }^{a, c} \dagger$ \\ Departments of a Biomedical Engineering and ' Neurobiology and Physiology, Northwestern University, \\ Evanston, IL 60208, and ${ }^{\mathrm{b}}$ Department of Biological Sciences, University of Cincinnati, Cincinnati, \\ OH 45221, U.S.A.
}

(Received Houston 15 August 1994 and accepted in revised form 28 February 1995)

\begin{abstract}
Transient changes in retinal oxygen in response to light stimuli were studied to further understand the light-evoked change in oxygen consumption. Double-barreled microelectrodes, which measured oxygen and local voltage simultaneously, were positioned near the photoreceptor inner segments of the toad neural retina-retinal pigment epithelium-choroid preparation. Light-evoked oxygen responses were measured in a normal $\left[\mathrm{Na}^{+}\right]$solution, and in a test solution with lowered extracellular $\left[\mathrm{Na}^{+}\right]$to inhibit $\mathrm{Na}^{+} / \mathrm{K}^{+}$pumping. Under the normal $\left[\mathrm{Na}^{+}\right]$condition, retinal oxygen tension increased in response to light indicating that oxygen utilization had decreased. When the $\mathrm{Na}^{+}$concentration was lowered in the retina, the oxygen tension decreased in response to light, indicating an increase in oxygen utilization which was smaller than the $\mathrm{Na}^{+} / \mathrm{K}^{+}$pump effect and therefore masked under normal conditions. The increase in oxygen utilization in lowered [ $\left.\mathrm{Na}^{+}\right]$was suppressed by adding $0.7 \mathrm{mM}$ 3-isobutyl-1-methyl-xanthine, a phosphodiesterase inhibitor, suggesting that the response was largely due to hydrolysis and subsequent resynthesis of cyclic GMP. Results of fitting the light-evoked responses to exponential functions suggested that the decrease in oxygen consumption caused by slowing of the photoreceptor $\mathrm{Na}^{+} / \mathrm{K}^{+}$ATPase had a time constant between 130 and $180 \mathrm{sec}$ and that the increase in oxygen utilization from increased cyclic GMP synthesis was faster.

(C) 1995 Academic Press Limited

Key words: retina; oxygen; oxygen metabolism; light response; photoreceptor.
\end{abstract}

\section{Introduction}

In the retina of both frog and toad, inhibition of the photoreceptor $\mathrm{Na}^{+} / \mathrm{K}^{+}$ATPase decreases photoreceptor oxygen consumption $\left(\mathrm{QO}_{2}\right)$ by at least a factor of two (Kimble, Svoboda and Ostroy, 1980; Zuckerman and Weiter, 1980; Haugh-Scheidt, Linsenmeier and Griff, 1995), indicating that this pump requires a large part of the energy used by the photoreceptors. Furthermore, the light-evoked decrease in photoreceptor $\mathrm{QO}_{2}$ is believed to reflect a slowing of the rate of sodium pumping by their $\mathrm{Na}^{+} / \mathrm{K}^{+}$ATPase. In light, the $\mathrm{Na}^{+}$influx is reduced (e.g. Woodruff, Fain and Bastian, 1982), thereby decreasing the need for $\mathrm{Na}^{+}$ pumping. Under conditions which inhibited $\mathrm{Na}^{+} / \mathrm{K}^{+}$ pumping, however, the light-evoked change in photoreceptor $\mathrm{QO}_{2}$ was not abolished, but reversed (Kimble et al., 1980). This increase in $\mathrm{QO}_{2}$ probably originated from the photoreceptors, since it persisted during aspartate treatment. A light-induced increase in cGMP synthesis has been found in the toad retina (Dawis et al., 1988), and this could be responsible for a lightevoked increase in $\mathrm{QO}_{2}$ in the photoreceptors. Some direct evidence for this was reported in rabbit retina by

\footnotetext{
* Present address: Department of Ophthalmology and Visual Sciences, University of Illinois College of Medicine, 1855 West Taylor Street, Chicago, IL 60612, U.S.A.

t For correspondence at: Department of Biomedical Engineering, Northwestern University, 2145 Sheridan Road, Evanston. IL 60208-3107, U.S.A.
}

Ames et al. (1992) and by a preliminary report of the present work (Haugh, Griff and Linsenmeier, 1991).

The present work was undertaken to characterize the light-evoked increase in $\mathrm{QO}_{2}$ and to determine whether there are two processes (or possibly more) whose metabolic needs change substantially with illumination. The pharmacology of these $\mathrm{PO}_{2}$ changes was examined to better identify the light-dependent processes which affect photoreceptor $\mathrm{QO}_{2}$, and to investigate whether the light-evoked increase in $\mathrm{QO}_{2}$ reflects an increase in cGMP synthesis. In addition, the amplitudes, sensitivities, and time courses of the processes were compared. These questions were addressed by examining transient, light-evoked changes in retinal $\mathrm{PO}_{2}\left(\mathrm{PO}_{2}\right.$ responses) that were measured from the in vitro toad retina during normal function and when $\mathrm{Na}^{+} / \mathrm{K}^{+}$pumping was inhibited.

\section{Materials and Methods}

A description of the toad retina preparation and recording of electrical signals is found in the companion paper (Haugh-Scheidt et al., 1995). Briefly, intraretinal $\mathrm{PO}_{2}$ and local electroretinogram (ERG) were recorded with double-barreled microelectrodes in normal $\left[\mathrm{Na}^{+}\right]$and in low $\left[\mathrm{Na}^{+}\right]$solutions. In low $\left[\mathrm{Na}^{+}\right]$ solutions, $\left[\mathrm{Ca}^{\mathrm{2}}\right]$ was buffered at a markedly reduced level to prevent a large influx of $\mathrm{Ca}^{2+}$ into the photoreceptors (Haugh-Scheidt et al.,, 1995). Retinas were dark-adapted for at least $2 \mathrm{hr}$ after dissection. 


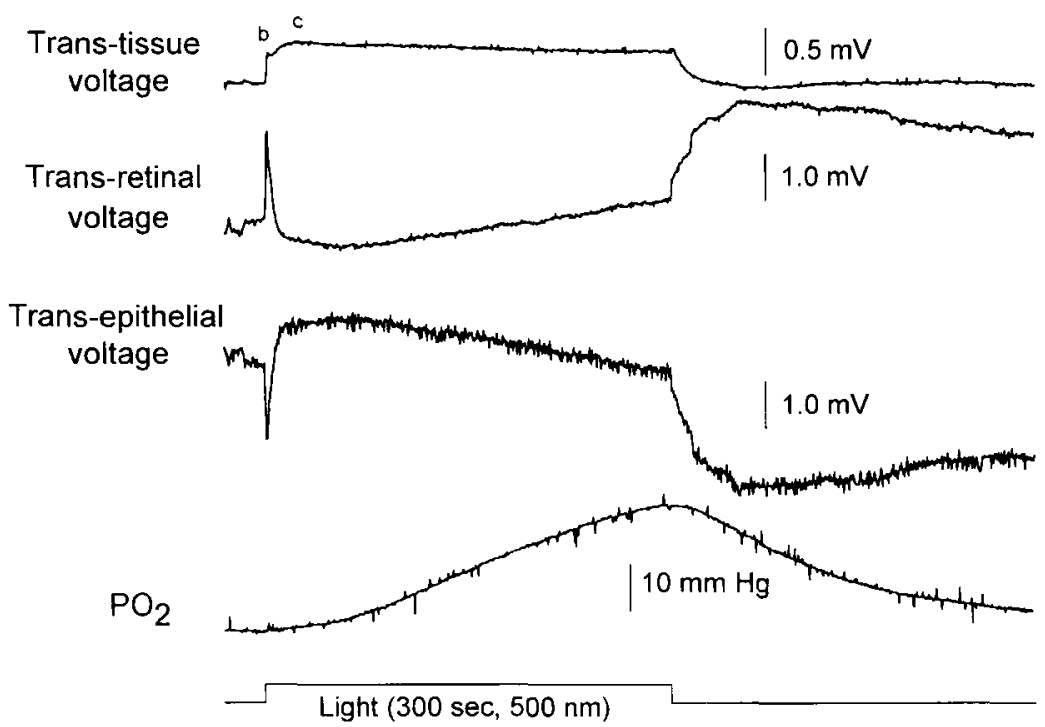

FIG. 1. Measurement of the light-evoked retinal responses. A microelectrode positioned in the outer retina recorded the transretinal and trans-epithelial voltages along with retinal $\mathrm{PO}_{2}$. The trans-tissue voltage was recorded simultaneously. The stimulus level (at $500 \mathrm{~nm}$ for $300 \mathrm{sec}$ ) was about $2 \mathrm{log}$ units below saturation of the c-wave. The b- and c-waves of the trans-tissue response are indicated on the trace. The trans-tissue voltage is given at twice the gain of the microelectrode voltages. Retinal $\mathrm{PO}_{2}$ increased during illumination and returned to its baseline while the retina was in darkness (not completely shown). (Data $=44$ LLR 18.)

\section{Measurement of Retinal $\mathrm{PO}_{2}$ Responses to Light}

To measure light-induced $\mathrm{PO}_{2}$ changes, the $\mathrm{O}_{2}$ microelectrode was positioned in the outer retina by first advancing through the retinal pigment epithelium (RPE) and then withdrawing about $70 \mu \mathrm{m}$ into the neural retina, close to the minimum $\mathrm{PO}_{2}$ in this preparation and at the level of the inner segments. An example of the microelectrode recordings in response to $300 \mathrm{sec}$ of illumination is shown in Fig. 1. The ERG measured across the tissue is the sum of the transretinal and trans-epithelial voltages recorded by the microelectrode. Retinal $\mathrm{PO}_{2}$ increased in response to light when the retina was superfused with a normal $\left[\mathrm{Na}^{+}\right]$solution. Light-evoked $\mathrm{PO}_{2}$ responses were recorded for $300 \mathrm{sec}$ of illumination at different stimulus levels. For longer responses that were recorded, the $\mathrm{PO}_{2}$ reached a steady level by $600 \mathrm{sec}$. The unattenuated illumination $(500 \mathrm{~nm})$ was about $8 \times 10^{6}$ quanta $\left(\mu \mathrm{m}^{2} \mathrm{sec}\right)^{-1}$, and neutral density filters were added for dimmer illumination. The retina was allowed to dark adapt for at least $15 \mathrm{~min}$ between responses, or until the b-wave returned to its darkadapted amplitude.

\section{Modelling Light-evoked $\mathrm{PO}_{2}$ Responses}

The light-evoked $\mathrm{PO}_{2}$ response was modelled as an exponential function, or as the sum of two exponential functions, as a means of describing the time course of the processes that affect retinal $\mathrm{QO}_{2}$. The purpose of the modelling was to describe mathematically the $\mathrm{PO}_{2}$ changes and then, hopefully, relate the quantitative results to cellular processes. For the single exponential model, the time dependent $\mathrm{PO}_{2}$ change was described by:

$$
\begin{array}{r}
P=P_{0} \quad 0 \leqslant t \leqslant t d \\
P=P_{0}+\left(P_{\infty}-P_{0}\right)\left\{1-\exp \left(\frac{-(t-t d)}{\tau}\right)\right\} \\
t \geqslant t d
\end{array}
$$

In this model, $P_{0}$ is the initial $\mathrm{PO}_{2}$ and $P_{\infty}$ is the steady state $\mathrm{PO}_{2}$ during illumination. The time delay, $t d$, is the time between light onset and the initial change in $\mathrm{PO}_{2}$. The response has an amplitude of $P_{\infty}-P_{0}$ and a time constant of $\tau$.

The second model that was used to describe the light-evoked $\mathrm{PO}_{2}$ change was the sum of two exponential functions with delay times, $t d_{1}$ and $t d_{2}$, and time constants, $\tau_{1}$ and $\tau_{2}$. For $t d_{1}<t d_{2}$, the time dependent $\mathrm{PO}_{2}$ change was described by:

$$
\begin{gathered}
P=P_{0} \quad 0 \leqslant t \leqslant t d_{1} \\
P=P_{0}+P_{1}\left\{1-\exp \left(\frac{-\left(t-t d_{1}\right)}{\tau_{1}}\right)\right\} \\
P=P_{0}+P_{1}\left\{1-\exp \left(\frac{-\left(t-t d_{1}\right)}{\tau_{1}}\right)\right\} \\
+P_{2}\left\{1-\exp \left(\frac{-\left(t-t d_{2}\right)}{\tau_{2}}\right)\right\} \quad t \geqslant t d_{2}
\end{gathered}
$$

The parameters $P_{1}$ and $P_{2}$ are the magnitudes of the two exponential functions. The steady state $\mathrm{PO}_{2}$ during illumination, $P_{\infty}$, is equal to $P_{0}+P_{1}+P_{2}$. The amplitude of the response is $P_{1}+P_{2}$. The optimal parameter values were found by fitting the models to responses using a nonlinear least-squares routine that employed Marquardt's method (Press et al., 1989) to minimize 
the sum of the squared error between the model and the data. Other similar models were tested, for example using only one delay time or using the same delay time for both exponential functions. These were found to give larger confidence intervals for the parameters and in some cases the fits did not even converge on a set of parameters.

The $95 \%$ confidence interval for $P_{0}$ was about $\pm 0.5 \mathrm{mmHg}$, and for $t d, t d_{1}$ and $t d_{2}$ was within $\pm 4 \mathrm{sec}$. For the single exponential model, the parameters $P_{\infty}$ and $\tau$ were closely correlated within a fit (coefficient of correlation $>0.9$ ). As $\tau$ increased $P_{\infty}$ became smaller $\left(P_{0}-P_{\infty}\right.$ grew larger), with little reduction in error. This probably occurred because not all responses reached a clear plateau during $300 \mathrm{sec}$ of illumination. The values of $\tau$ reported are the smallest ones yielding good fits. For the two exponential model, the parameters $P_{1}, P_{2}, \tau_{1}$ and $\tau_{2}$, were highly correlated (coefficients of correlation $>0.9$ ). For $\tau_{1}$ and $\tau_{2}$, there was a negative correlation, i.e. as $\tau_{1}$ grew $\tau_{2}$ diminished. For fits in which the confidence intervals were large, the reported parameter values were found by fixing $\tau_{1}$ about $10 \mathrm{sec}$ above its lower limit and allowing the other parameters to adjust. This adjustment did not change the error of the fit. Thus, the reported $\tau_{1}$ may be an underestimate, but it is not likely to be an overestimate of the actual value. Likewise, the reported $\tau_{2}$ is probably an upper limit.

\section{Results}

\section{$\mathrm{PO}_{2}$ Responses to Light in Normal $\left[\mathrm{Na}^{+}\right]$}

Transient retinal $\mathrm{PO}_{2}$ responses to illumination $(n=$ $144 ; 30$ toads) were measured in the outer retina during 300-sec periods of illumination at different light levels. The threshold for detecting the $\mathrm{PO}_{2}$ response was about a log unit above the threshold for detecting a voltage response. Light-evoked $\mathrm{PO}_{2}$ responses and the corresponding trans-tissue voltage responses are shown in Fig. 2 for stimuli of increasing illumination. The time course of the $\mathrm{PO}_{2}$ change was much slower than any component of the ERG. In Fig. 2(A), the $\mathrm{PO}_{2}$ did not change much during the first $30-40 \mathrm{sec}$ of illumination, and then the $\mathrm{PO}_{2}$ increased for the duration of the light stimulus. For an illumination that saturated the oxygen response, the $\mathrm{PO}_{2}$ usually returned to baseline within $600 \mathrm{sec}$. Sometimes the light-evoked $\mathrm{PO}_{2}$ response had a slightly different shape, decreasing initially and then increasing as shown in Fig. 2(B). The dip in the beginning of the response was smallest for the lowest light level and, with increasing illumination, its amplitude did not change as much as the subsequent $\mathrm{PO}_{2}$ increase. This biphasic type of response was seen regularly, but less often than the monotonic type of response shown in Fig. 2(A). In any one tissue the response was always one type, either an initial increase or an initial decrease in $\mathrm{PO}_{2}$. The shape of the response was not correlated with the sensitivity of the retina. The initial $\mathrm{PO}_{2}$ decrease that was observed in some responses was not expected, but has also been observed from single rod photoreceptors of the salamander retina (Poitry et al., 1993).

The amplitudes of both the c-wave of the ERG and the $\mathrm{PO}_{2}$ response increased as stimulus magnitude increased. The c-wave, rather than the b-wave, was used as a measure of the retinal electrical activity because it was a prominent component of these responses and because its integration time was more similar to the $\mathrm{PO}_{2}$ change. Plots of the peak response to different illuminations in a single retina (intensity series) were examined in ten experiments. The responses were normalized to the maximal response within each retina, and are shown in Fig. 3(A) with points from the same retina connected. The $\mathrm{PO}_{2}$ response increased in amplitude through 3 to $4 \mathrm{log}$ units of illumination and then saturated. The shape of the intensity-response plots were quite similar across retinas, but the threshold for detecting a $\mathrm{PO}_{2}$ response varied over more than $2 \log$ units of illumination. The sensitivity of the retina was related to the length of time it had been in the dark after dissection, which varied from 2 to $10 \mathrm{hr}$. The illumination required to produce a half-maximal $\mathrm{PO}_{2}$ response was highly correlated $(r=0.96)$ to the stimulus required for a half-maximal c-wave response (not shown).

\section{$\mathrm{PO}_{2}$ Responses to Light in Lowered $\left[\mathrm{Na}^{+}\right]$}

A substantial portion of the normal light-evoked $\mathrm{PO}_{2}$ change in the retina is thought to be due to a decrease in the demand for $\mathrm{Na}^{+}$pumping in the photoreceptor inner segments. When a low $\left[\mathrm{Na}^{+}\right]$-low $\left[\mathrm{Ca}^{2+}\right]$ solution was used in this preparation, a substantial amount of extracellular $\mathrm{Na}^{+}$was removed from the retina, as determined by the disappearance of the b-wave and c-wave (not shown). Although there was no $\mathrm{Na}^{+}$in the superfusate, it was unlikely that the $\left[\mathrm{Na}^{+}\right]$was zero in the subretinal space because there were multiple layers of the retina to diffuse through. A combination of low $\left[\mathrm{Na}^{+}\right]$and ouabain, however, did not produce a larger effect than low $\left[\mathrm{Na}^{+}\right]$alone, suggesting that low $\left[\mathrm{Na}^{+}\right]$completely inhibited the pump. After the flow of solution into the retinal bath was switched to the low $\left[\mathrm{Na}^{+}\right]$solution, the $\mathrm{PO}_{2}$ increased slowly and took about $30 \mathrm{~min}$ to reach a steady level. Sometimes $\mathrm{PO}_{2}$ did not remain constant but continued to increase at a slow rate, about $0.8 \mathrm{mmHg} \mathrm{min}^{-1}$. In these cases the steady drift was subtracted from the $\mathrm{PO}_{2}$ response.

With the microelectrode positioned in the outer retina about $70 \mu \mathrm{m}$ from the RPE, light-evoked $\mathrm{PO}_{2}$ responses ( 93 responses from 16 toads) were measured during $300 \mathrm{sec}$ of illumination while the retina was in low $\left[\mathrm{Na}^{+}\right]$-low $\left[\mathrm{Ca}^{2+}\right]$. The light-evoked $\mathrm{PO}_{2}$ response in low $\left[\mathrm{Na}^{+}\right]$was very different from the $\mathrm{PO}_{2}$ response while the retina was in normal $\left[\mathrm{Na}^{+}\right] \mid$as shown in Fig. 
A

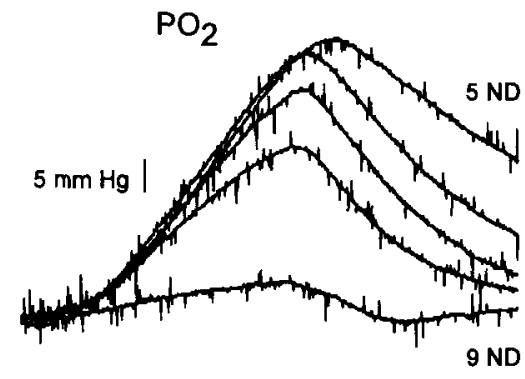

Trans-tissue voltage

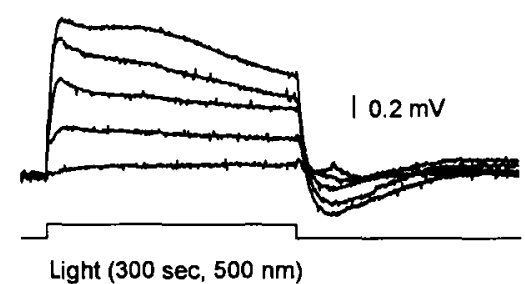

B

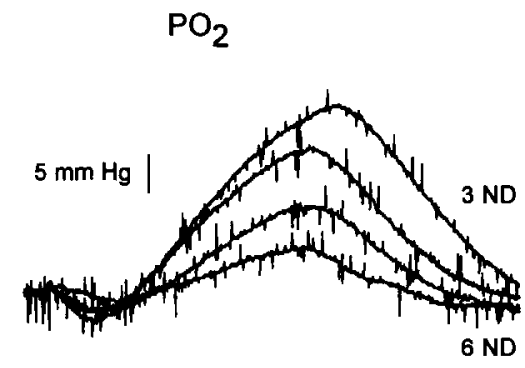

Trans-tissue voltage

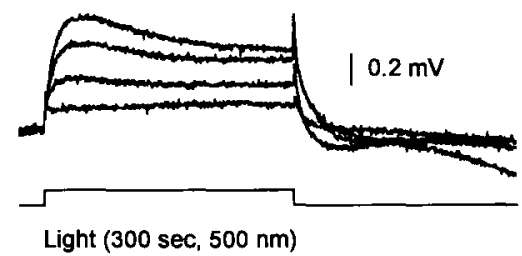

FIG. 2. Light-evoked $\mathrm{PO}_{2}$ responses measured in the outer retina. Retinal $\mathrm{PO}_{2}$ (top) and the corresponding trans-tissue voltage (bottom) were measured in response to illumination that was increased by a factor of 10 between responses as indicated by $\log$ attenuation provided by neutral density (ND) filters. The b-wave is obscured by overlying responses. Light evoked an increase in intraretinal $\mathrm{PO}_{2}(\mathrm{~A})$. In some retinas (B), light caused an initial decrease, followed by an increase in $\mathrm{PO}_{2}$. $($ Data $=44 L L R 16-20$ and 51LLR03-06.)

A

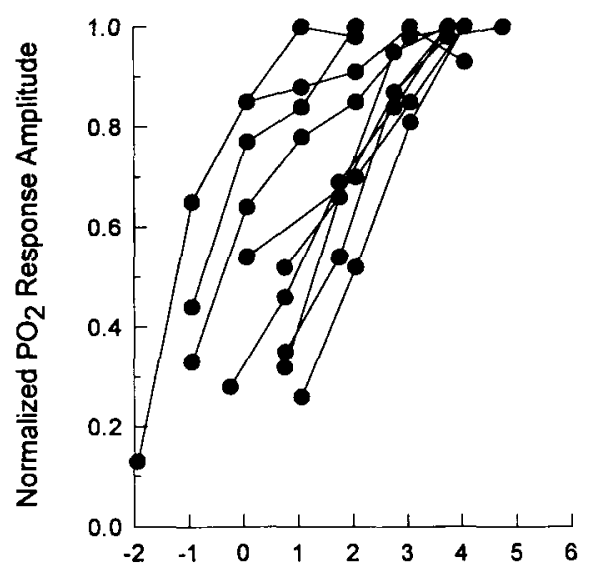

Log Illumination (log quanta/( $\left(\mathrm{um}^{2} \cdot \mathrm{sec}\right)$ )
B

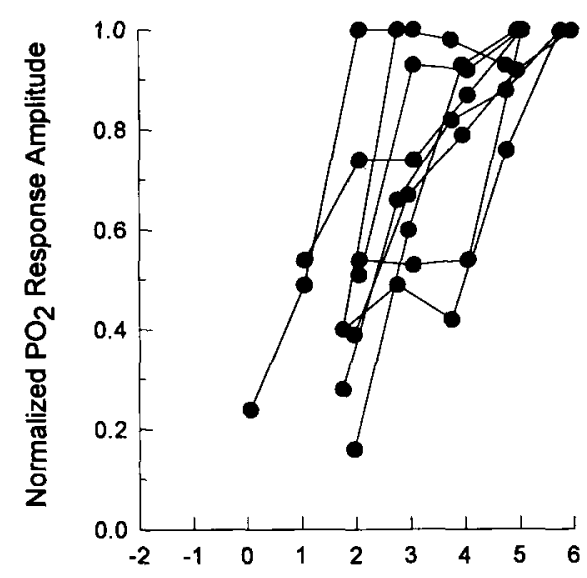

Log Illumination $\left(\log\right.$ quanta/ $\left.\left(\mu \mathrm{m}^{2} \cdot \mathrm{sec}\right)\right)$

FIG. 3. Intensity series of $\mathrm{PO}_{2}$ responses. The normalized $\mathrm{PO}_{2}$ response amplitudes, measured in normal $\left[\mathrm{Na}^{+}\right](\mathrm{A}$, positive amplitude) and in low $\left[\mathrm{Na}^{+}\right]$( $\mathrm{B}$, negative amplitude), are plotted as a function of illumination. Responses from the same retina are connected by a line. The response amplitude increased through $3-4 \log$ units, and in general, $\mathrm{PO}_{2}$ responses in low [Na ${ }^{+}$] were less sensitive than responses in normal $\left[\mathrm{Na}^{+}\right]$.

4. In low $\left[\mathrm{Na}^{+}\right]$, the $\mathrm{PO}_{2}$ increase was replaced with a retinal $\mathrm{PO}_{2}$ decrease during illumination. The amplitude of the response increased as light intensity increased, but for the same light level the magnitude of the response in normal $\left[\mathrm{Na}^{+}\right]$was larger than the corresponding $\mathrm{PO}_{2}$ response in low $\left[\mathrm{Na}^{+}\right]$. The $\mathrm{PO}_{2}$ responses in low $\left[\mathrm{Na}^{+}\right]$did not usually saturate at the same illumination as $\mathrm{PO}_{2}$ responses in normal $\left[\mathrm{Na}^{+}\right]$. The $\mathrm{PO}_{2}$ decrease in low $\left[\mathrm{Na}^{+}\right]$appeared to have a shorter latency following the onset of light than the latency of the $\mathrm{PO}_{2}$ increase in normal $\left[\mathrm{Na}^{+}\right]$. This timing was consistent with the biphasic responses sometimes observed in normal $\left[\mathrm{Na}^{+}\right]$(Fig. 3). In two experiments, $\left[\mathrm{Ca}^{2+}\right]$ was buffered at a low level by adding $2 \cdot 0 \mathrm{mM}$ EGTA to the normal $\left[\mathrm{Na}^{+}\right]$solution to determine whether low $\left[\mathrm{Ca}^{2+}\right]$ alone caused the $\mathrm{PO}_{2}$ to decrease in response to light. In fact, in normal $\left[\mathrm{Na}^{+}\right]$-low $\left[\mathrm{Ca}^{2+}\right]$, there was a larger light-evoked $\mathrm{PO}_{2}$ increase (not shown).

The intensity series from nine experiments were 


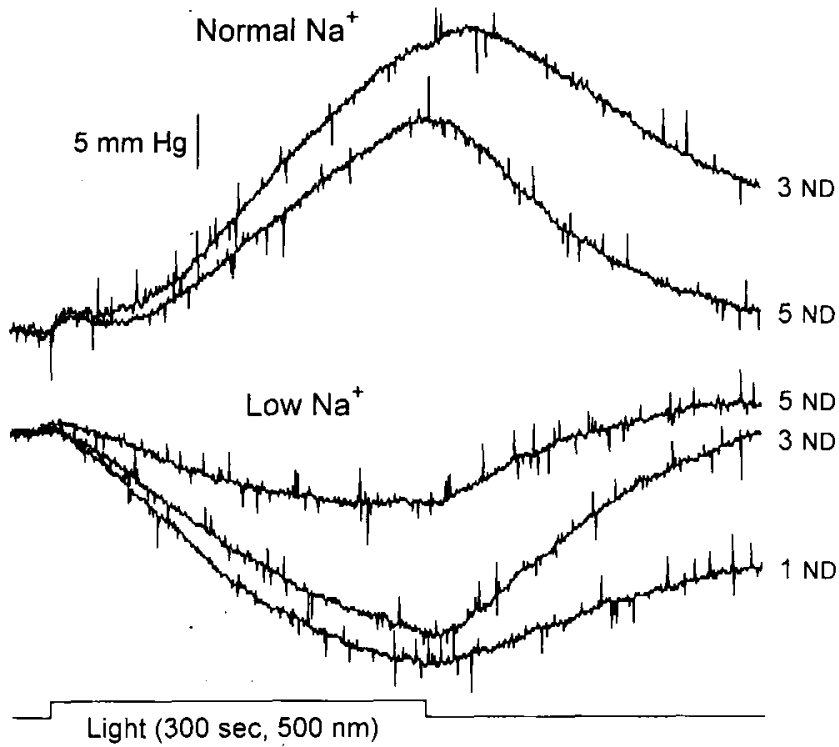

FIG. 4. Effect of lowered $\left[\mathrm{Na}^{+}\right]$on the light-evoked $\mathrm{PO}_{2}$ response. The response of retinal $\mathrm{PO}_{2}$ measured in normal $\left[\mathrm{Na}^{+}\right]$at two light levels was a large increase in $\mathrm{PO}_{2}$. When the superfusate was changed to a $0 \mathrm{Na}^{+}$solution, the lightevoked $\mathrm{PO}_{2}$ response changed to a decrease in $\mathrm{PO}_{2}$. The unattenuated illumination was $9.2 \times 10^{6}$ quanta $\left(\mu \mathrm{m}^{2} \mathrm{sec}\right)^{-1}$. $($ Data $=41$ LLR09-11, 13, 15. $)$

examined by normalizing to the maximum response amplitude as shown in Fig. 3(B). The points from a single retina are connected by a line. The threshold for detecting a response varied over about $2 \log$ units of illumination, and the response amplitudes increased through 3 to $4 \log$ units of illumination. It required about $2 \log$ units less light to detect a light-evoked $\mathrm{PO}_{2}$ response in normal $\left[\mathrm{Na}^{+}\right]$than in low $\left[\mathrm{Na}^{+}\right]$-low $\left[\mathrm{Ca}^{2+}\right]$. Thus, the average half-maximal response was at $2.3 \mathrm{log}$ quanta $\left(\mu \mathrm{m}^{2} \mathrm{sec}\right)^{-1}$ in low [ $\left.\mathrm{Na}^{+}\right]$[Fig. 3(B)] as compared to $0.4 \log$ quanta $\left(\mu \mathrm{m}^{2} \mathrm{sec}\right)^{-1}$ in normal $\left[\mathrm{Na}^{+}\right]$[Fig. 3(A)]. Retinas that had a high sensitivity in normal $\left[\mathrm{Na}^{+}\right]$tended to also have higher sensitivity in low $\left[\mathrm{Na}^{+}\right]$.

\section{Origin of the Light-evoked $\mathrm{PO}_{2}$ Response in Low $\left[\mathrm{Na}^{+}\right]$}

The light-evoked $\mathrm{O}_{2}$ utilization change could have originated in cells that were affected by photoreceptors or in the photoreceptors themselves, and to investigate this, $40 \mathrm{~mm}$ aspartate was added to the superfusate. Aspartate mimics the endogenous photoreceptor transmitter and saturates postsynaptic receptors so that second order retinal cells cannot detect a change of transmitter release during illumination. The effect of aspartate on the ERG was to abolish the b-wave, but the c-wave was still observed. As shown in Fig. 5, the normal $\left[\mathrm{Na}^{+}\right] \mathrm{PO}_{2}$ response and the low $\left[\mathrm{Na}^{+}\right] \mathrm{PO}_{2}$ response both persisted, indicating that the $\mathrm{QO}_{2}$ change occurred in the photoreceptors $(n=3)$.

The light-evoked increase in $\mathrm{O}_{2}$ utilization observed when $\mathrm{Na}^{+}$pumping was inhibited could be due to some component of phototransduction. For example, many molecules of cGMP are hydrolysed as a result of

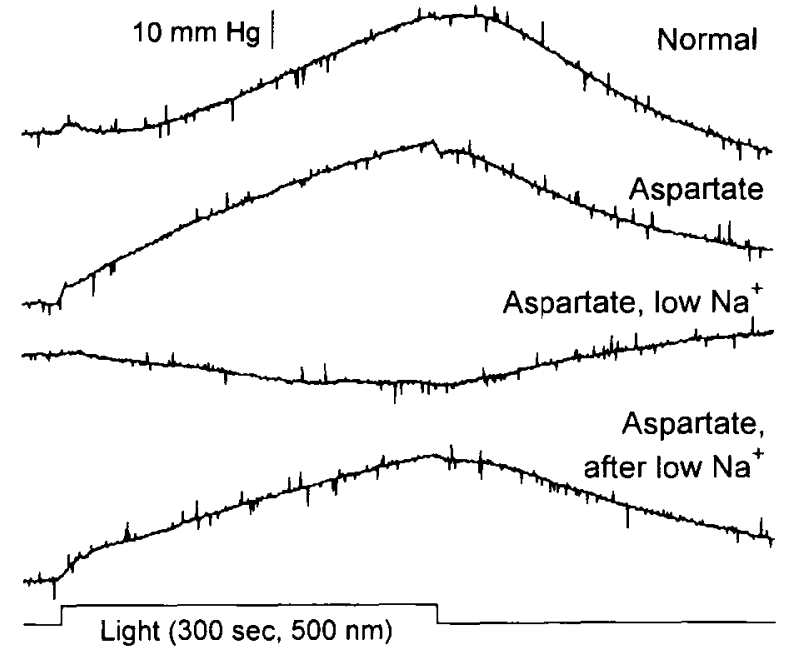

FIG. 5. Effect of aspartate. In a normal $\left[\mathrm{Na}^{+}\right]$solution, retinal $\mathrm{PO}_{2}$ increased upon illumination and that response persisted when aspartate was added to the superfusate and the stimulus repeated. The $\mathrm{PO}_{2}$ response in lowered $\left[\mathrm{Na}^{+}\right]$ and aspartate was a $\mathrm{PO}_{2}$ decrease just as it had been in the absence of aspartate (Fig. 4). The bottom trace shows recovery of the light-evoked $\mathrm{PO}_{2}$ response when $\left[\mathrm{Na}^{+}\right]$was reintroduced to the retina. All responses were recorded from the same retina in the order presented. (Data $=42 \mathrm{LLR02}, 4$, $5,9$.

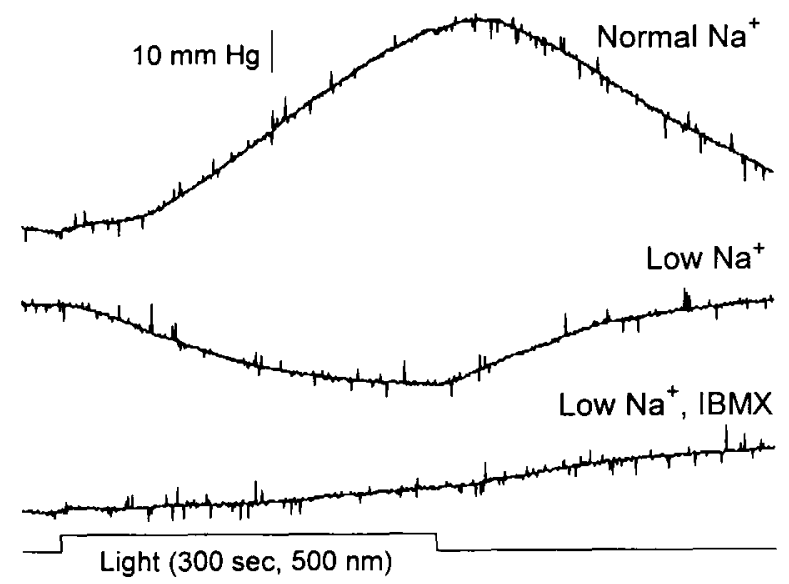

FIG. 6. Effect of IBMX. A light-evoked $\mathrm{PO}_{2}$ response measured in normal $\left[\mathrm{Na}^{+}\right]$exhibits a $\mathrm{PO}_{2}$ increase. $\mathrm{A} \mathrm{PO}_{2}$ response measured in the same retina after lowering $\left[\mathrm{Na}^{+}\right]$ (and low $\left[\mathrm{Ca}^{2+}\right]$ ), results in a $\mathrm{PO}_{2}$ decrease (same stimulus). When IBMX $(0.7 \mathrm{~mm})$ was added to the superfusate, still in lowered $\left[\mathrm{Na}^{+}\right]$, the $\mathrm{PO}_{2}$ decrease was inhibited. Similar results were obtained in eight of nine retinas examined. $($ Data $=45$ LLR21, 24, 27).

rhodopsin absorbing photons, and the resynthesis of cGMP requires a supply of ATP. To test this hypothesis, the rate of cGMP turnover was manipulated by adding IBMX (3-isobutyl-1-methyl-xanthine), which is known to block the action of phosphodiesterase (PDE), to the low $\left[\mathrm{Na}^{+}\right]-$low $\left[\mathrm{Ca}^{2+}\right]$ superfusate. By inhibiting the hydrolysis of cGMP to GMP, it was expected that any light-dependent increase in cGMP turnover would be inhibited. Adding IBMX to the low $\left[\mathrm{Na}^{+}\right]-$low $\left[\mathrm{Ca}^{2+}\right]$ superfusate produced little change in baseline $\mathrm{PO}_{2}$ measured in the outer retina. The major effect of 0.7 mM IBMX, shown in Fig. 6, was to inhibit the 
A

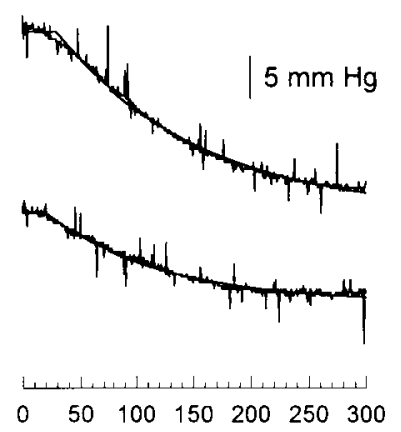

$\mathbf{B}$

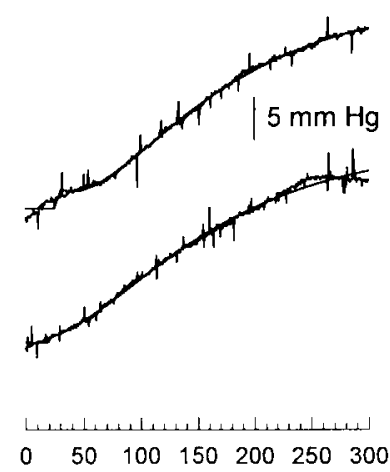

C

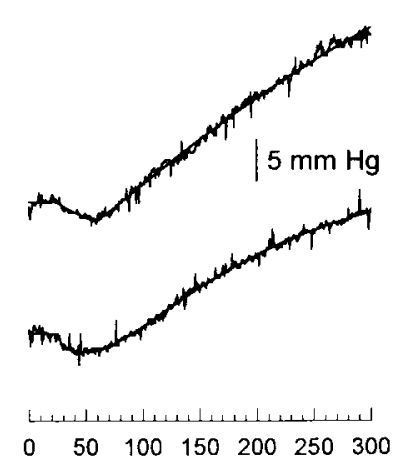

Time after onset of Illumination (sec)

FIG. 7. Single exponential model (A) and two exponential model [(B) and (C)] fitted to light-evoked $\mathrm{PO}_{2}$ responses. (A) Two $\mathrm{PO}_{2}$ responses that were measured in lowered $\left[\mathrm{Na}^{+}\right]$were fitted with the single exponential model. The parameter values were: $\tau=127, t d=29$ (top trace), and $\tau=102, t d=20$ (bottom trace). (B) Two $\mathrm{PO}_{2}$ responses that were measured in normal [Na $\left.\mathrm{Na}^{+}\right]$ were fitted with the two exponential model. The parameter values were: $\tau_{1}=60, t d_{1}=40, \tau_{2}=158, t d_{2}=38$ (top trace), and $\tau_{1}=60, t d_{1}=21, \tau_{2}=104, t d_{2}=20$ (bottom trace). (C) Another two $\mathrm{PO}_{2}$ responses fitted with the two exponential model. The parameter values were: (A) $\tau_{1}=68, t d_{1}=33, \tau_{2}=250, t d_{2}=55$, and $\tau_{1}=40, t d_{1}=25, \tau_{2}=142$, and $t d_{2}=28$ (bottom trace). In each panel, the responses were from the same retina and the top trace is in response to a stimulus of 100 -fold greater illumination. Values are given in seconds. The mean values from all retinas examined are given in Table I. (Data $=43 \mathrm{LLR03}$, 4, 38LLR01, 3, 47LLR07, 8.)

\section{Table I}

Parameter values (mean \pm s.D.) from the exponential models fitted to light-evoked $\mathrm{PO}_{2}$ responses. For the two exponential model, the subscript 1 and 2 refer to the decreasing and the increasing exponentials, respectively. The units of $\tau$ and td are seconds. ( $n=$ number of responses $)$

\begin{tabular}{lrrrrrrr}
\hline & $n$ & $\tau$ & $t d$ & $\tau_{1}$ & $t d_{1}$ & $\tau_{2}$ & $t d_{2}$ \\
\hline Single exponential model & & & & & & & \\
$\quad$ Low [ $\left.\mathrm{Na}^{+}\right]($decreasing exponential) & 93 & $156 \pm 66$ & $38 \pm 22$ & & & & \\
$\quad$ Normal $\left[\mathrm{Na}^{+}\right]$(increasing exponential) & 13 & $131 \pm 46$ & $57 \pm 26$ & & & & \\
$\quad$ Two exponential model & 131 & & & $68 \pm 21$ & $42 \pm 18$ & $180 \pm 64$ & $41 \pm 20$ \\
$\quad$ Normal $\left[\mathrm{Na}^{+}\right]$ & & & &
\end{tabular}

light-evoked $\mathrm{PO}_{2}$ decrease in low $\left[\mathrm{Na}^{+}\right]$-low $\left[\mathrm{Ca}^{2+}\right]$. The light-evoked $\mathrm{PO}_{2}$ response recovered after the IBMX solution was replaced with control Ringer's solution. In fact, the effect of IBMX did not persist through a long exposure (about $60 \mathrm{~min}$ ); however, a better inhibitor of PDE or guanylate cyclase was not available.

\section{Modelling the Light-evoked $\mathrm{PO}_{2}$ Response}

Exponential functions were used to describe the time course of the light-evoked $\mathrm{PO}_{2}$ change in the retina. In lowered $\left[\mathrm{Na}^{+}\right]$, the light-evoked $\mathrm{PO}_{2}$ response was less complicated since a monotonic decrease in retinal $\mathrm{PO}_{2}$ was always observed, and the response could always be fitted to the single exponential model. Figure $7(\mathrm{~A})$ shows two responses fitted to the model. During the time delay the model did not fit the data precisely in the top trace, but the overall model fitted with $30 \%$ less sum-of-squares error when the delay was included as compared to when the delay was omitted. The mean parameter values, given in Table I, were not highly correlated with the stimulus strength.

For light-evoked retinal $\mathrm{PO}_{2}$ responses measured in normal $\left[\mathrm{Na}^{+}\right]$, a few responses were fitted well by the single exponential model (Table I). These responses were from stimuli at lower illumination, which did not usually generate a detectable $\mathrm{PO}_{2}$ response in lowered $\left[\mathrm{Na}^{+}\right]$. The remaining 131 responses, which could not be fitted to a single exponential function, were fitted reasonably well by the two exponential model, and required one decreasing exponential function $\left(P_{1}, \tau_{1}\right.$ and $\left.t d_{1}\right)$ and one increasing exponential function $\left(P_{2}\right.$ $\tau_{2}$ and $t d_{2}$ ), although this was not fixed in the model. Responses fitted to the two exponential model are shown in Fig. $7(\mathrm{~B})$ and $(\mathrm{C})$. When $t d_{1}$ was less than $t d_{2}$, the fitted curve decreased, and then increased, as was seen in some of the data. For $\mathrm{PO}_{2}$ responses fitted by the two exponential model, the time constant of the decreasing exponential term, $\tau_{1}$, was always smaller 
than $\tau_{2}$ (Table I). In addition, the absolute value of $P_{1}$ was always smaller than $P_{2}$, and the ratio of the amplitudes (absolute values), $P_{1} / P_{2}$, was $0 \cdot 43 \pm 0 \cdot 15$ ( $n$ $=131$ ). If these functions approximated the $\mathrm{PO}_{2}$ response of two photoreceptor processes, then the mechanism which lowered $\mathrm{PO}_{2}$ in light had about $43 \%$ of the effect of the mechanism which raised $\mathrm{PO}_{2}$.

\section{Discussion}

\section{Light-evoked $\mathrm{PO}_{2}$ Response}

In the toad retina, light evoked a robust increase in $\mathrm{PO}_{2}$, indicating a decrease in oxygen consumption as has been observed in other vertebrate retinas (e.g. Sickel, 1972 ; Linsenmeier, 1986). Light-induced $\mathrm{PO}_{2}$ changes in the retina must have ultimately originated in the photoreceptors. Pharmacological isolation of the photoreceptors with aspartate did not affect the light-evoked $\mathrm{PO}_{2}$ changes observed in normal or low $\left[\mathrm{Na}^{+}\right]$, suggesting that these $\mathrm{PO}_{2}$ changes must occur in the photoreceptors, Müller cells or RPE cells. A change in metabolism of the thin layer of RPE cells would not likely have much of an effect on retinal $\mathrm{PO}_{2}$. A contribution from Müller cells can not be completely ruled out, but frog Müller cells have few mitochondria in their cytoplasm in the outer retina (Uga and Smelser, 1973), suggesting that they would contribute little to the changes in metabolism during illumination. Inner retinal oxygen consumption also changes with light (Haugh-Scheidt et al., 1995), but this change is smaller than the one in the outer retina. It can be shown, by using the steady-state diffusion model in that paper and average values of the parameters, that the change in inner retinal consumption accounts for less than $10 \%$ of the lightevoked $\mathrm{PO}_{2}$ change recorded by an electrode located in the outer retina.

The light-evoked $\mathrm{PO}_{2}$ changes, therefore, are believed to reflect primarily changes in photoreceptor metabolism, and are expected to be rod dominated since the sensitivity was similar to that measured from toad rods (Fain, 1976). The illumination required for a half-maximal response from single toad rods, measured by Fain (1976), was in the upper end of the range of illuminations which produced half-maximal $\mathrm{PO}_{2}$ (and c-wave) responses in this study. Amphibian retinas also contain cones (Liebman and Entine, 1968) which absorb maximally at $575 \mathrm{~nm}$, and the cone population in the toad retina is substantial (Zhang and Straznicky, 1991), but their size and their percentage of total photopigment is small compared to the rods. Furthermore, a cone contribution to the b-wave could not be detected when a comparison was made between responses to 500 and $600 \mathrm{~nm}$ illumination at light intensities used in this study.

Inhibition of the light-evoked $\mathrm{PO}_{2}$ increase in low $\left[\mathrm{Na}^{+}\right]-$low $\left[\mathrm{Ca}^{2+}\right]$ solution was not caused by the lowered $\left[\mathrm{Ca}^{2+}\right]$ since lowering $\left[\mathrm{Ca}^{2+}\right]$ alone produced a larger light-evoked $\mathrm{PO}_{2}$ increase. A possible explanation for that $\mathrm{PO}_{2}$ response is that lowering $\left[\mathrm{Ca}^{2+}\right]$ resulted in increased cGMP synthesis, more lightdependent channels open in the dark (e.g. Pepe et al., 1986: Koch and Stryer, 1988), and larger $\mathrm{Na}^{+}$ conductance. Thus, the light-induced reduction in $\mathrm{QO}_{2}$ when all the channels were closed would be larger because there had been more $\mathrm{Na}^{+}$pumping in the dark.

\section{Model of the Light-evoked $\mathrm{PO}_{2}$ Response}

Modelling the light-evoked $\mathrm{PO}_{2}$ responses as an exponential change in $\mathrm{PO}_{2}$ was a means of describing and quantifying the time course of the two processes that effect $\mathrm{QO}_{2}$. Diffusion of oxygen is rapid relative to the changes in $\mathrm{PO}_{2}$ observed, so the time course of $\mathrm{PO}_{2}$ changes is a direct measurement of the time course of consumption changes. Light-evoked $\mathrm{PO}_{2}$ responses in low $\left[\mathrm{Na}^{+}\right]$-low $\left[\mathrm{Ca}^{2+}\right]$ were closely fitted by a decreasing exponential function. Light-evoked $\mathrm{PO}_{2}$ responses in normal $\left[\mathrm{Na}^{+}\right]$could be detected at dimmer illumination than the responses in low $\left[\mathrm{Na}^{+}\right]$-low $\left[\mathrm{Ca}^{2+}\right]$. When the retina was in normal $\left[\mathrm{Na}^{+}\right]$, responses at weaker light levels could be fitted by a single increasing exponential function, whereas responses at stronger light levels required a model that was the sum of increasing and decreasing exponentials. The amplitude and the time constant of the decreasing exponential were always smaller.

The time constant of the increasing exponential, attributed to the slowing of the $\mathrm{Na}^{+}$pump, and subsequent slowing of oxidative phosphorylation was about $180 \pm 64 \mathrm{sec}$. These events are probably the same ones that are described by the responses at dim illumination which were fit by a single exponential. For those the time constant was $131 \pm 46 \mathrm{sec}$. These values are close to estimates of the time constant of the light-induced decrease in intracellular $\left[\mathrm{Na}^{+}\right]$, which ranged from 110 to $170 \mathrm{sec}$ (Shimazaki and Oakley, 1984). The similarity suggests that the rate dependent process for the metabolic change, as well as for the slowing of the rate of pumping, is the change in intracellular $\mathrm{Na}^{+}$concentration.

If the $\mathrm{PO}_{2}$ decrease is indeed a reflection of a change in cGMP turnover, then the time constant of the change in $\mathrm{PO}_{2}$ is likely to reflect the synthesis of cGMP. From the two-exponential model, the time constant of the decreasing exponential, attributed to cGMP resynthesis, was $68 \pm 24 \mathrm{sec}$, but this is a lower limit (see Results). From the responses in low $\left[\mathrm{Na}^{+}\right]$-low $\left[\mathrm{Ca}^{2+}\right]$, the time constant of this process was $156 \pm 66 \mathrm{sec}$. A possible explanation for this difference is that lowering $\left[\mathrm{Na}^{+}\right]$or simultaneously lowering $\left[\mathrm{Ca}^{2+}\right]$ had other effects besides inhibiting the $\mathrm{Na}^{+} / \mathrm{K}^{+}$ ATPase and that these affected the time course of cGMP resynthesis. In the physiological condition, light leads to a lowering of intracellullar $\left[\mathrm{Ca}^{2+}\right]$ and activation of guanylate cyclase, but when the $\mathrm{Ca}^{2+}$ 
activation of guanylate cyclase was manipulated, the time course of the photoresponse was changed (Gorczyca et al., 1994). Similarly, if the low $\left[\mathrm{Na}^{+}\right]$-low $\left[\mathrm{Ca}^{2+}\right]$ solution blocked the light-evoked lowering of intracellular $\left[\mathrm{Ca}^{2+}\right]$, then the time constant of cGMP synthesis in low $\left[\mathrm{Na}^{+}\right]$-low $\left[\mathrm{Ca}^{2+}\right]$ would be different than under physiological conditions.

\section{Two Competing Processes}

The light-induced decrease in retinal $\mathrm{QO}_{2}$ has been attributed to a slowing of the photoreceptor $\mathrm{Na}^{+} / \mathrm{K}^{+}$ ATPase. Lowering extracellular $\left[\mathrm{Na}^{+}\right]$inhibited the light-evoked $\mathrm{PO}_{2}$ increase and revealed a $\mathrm{PO}_{2}$ decrease, indicating that light also initiated events that increased oxygen consumption. The light-induced increase in oxygen consumption presumably occurs under normal $\left[\mathrm{Na}^{+}\right]$conditions, but is masked by the decrease in consumption due to the reduction of $\mathrm{Na}^{+} / \mathrm{K}^{+}$ATPase activity. The fact that both an increasing exponential and a decreasing exponential were usually needed to model the normal $\left[\mathrm{Na}^{+}\right]$response supports this conclusion. Under conditions which inhibit $\mathrm{Na}^{+} / \mathrm{K}^{+}$ ATPase, the light-evoked $\mathrm{PO}_{2}$ decrease has also been observed in frog (Kimble et al., 1980) and in rabbit (Ames et al., 1992).

The light-induced increase in $\mathrm{QO}_{2}$ was probably the result of some process of phototransduction; moreover, the synthesis of cGMP that has been hydrolyzed during phototransduction is likely to be the largest consumer of ATP (Dawis et al., 1989). When the hydrolysis of CGMP was inhibited indirectly by adding IBMX (in low $\left[\mathrm{Na}^{+}\right]$-low $\left[\mathrm{Ca}^{2+}\right]$ ), the light-evoked $\mathrm{PO}_{2}$ decrease was blocked. In a normal extracellular environment, the effect of IBMX on cGMP turnover could occur via two mechanisms. An IBMX-evoked increase in [cGMP] could: (1) open light-dependent channnels, increase $\mathrm{Ca}^{2+}$ influx and inhibit activation of guanylate cyclase mediated by low $\left[\mathrm{Ca}^{2+}\right]_{i}$, or (2) slow guanylate cyclase activity by cGMP-mediated product inhibition. In these low $\left[\mathrm{Na}^{+}\right]-$low $\left[\mathrm{Ca}^{2+}\right]$ experiments, the normal light-induced decrease in $\left[\mathrm{Ca}^{2+}\right]_{\mathrm{i}}$ is presumably inhibited by blocking $\mathrm{Na}^{+} / \mathrm{Ca}^{2+}$ exchange, and therefore the effect of IBMX on cGMP turnover is probably by product inhibition. Regardless of its mechanism of action, the inhibition by IBMX provides the first direct evidence that there is a lightevoked $\mathrm{QO}_{2}$ increase due to cGMP turnover. Furthermore, since the IBMX/low $\left[\mathrm{Na}^{+}\right]$combination eliminated all light-evoked $\mathrm{PO}_{2}$ changes, there are unlikely to be any further light-dependent processes that are energetically important.

A calculation of the absolute values of the energy utilization of each process would depend on knowing the contributions of glycolysis and of light-independent processes to the total metabolism. However, under the assumptions that cGMP synthesis is not seriously altered in low $\left[\mathrm{Na}^{+}\right]-$low $\left[\mathrm{Ca}^{2+}\right]$, that glycolysis is a minor component, and that the processes add linearly,

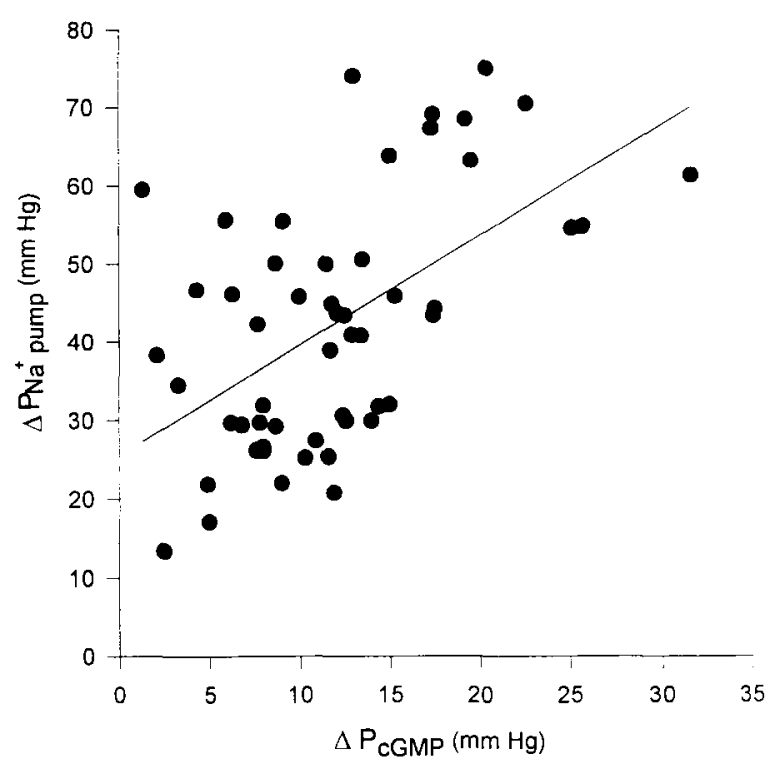

FIG. 8. $\mathrm{Na}^{+}$pump dependent and cGMP dependent $\mathrm{PO}_{2}$ changes. The light-evoked $\mathrm{PO}_{2}$ changes are plotted for $\mathrm{Na}^{+}-$ pump-dependent activity (calculated value) versus cGMPdependent activity (measured value) in the same retina. The $\mathrm{PO}_{2}$ change attributed to cGMP dependent activity was always smaller than the $\mathrm{PO}_{2}$ change attributed to $\mathrm{Na}^{+}$pump activity. The slope of the linear regression is $1.4(r=0.55)$.

then an estimate can be made of the relative changes in the metabolic demand of the two processes that occur during illumination. If one considers the lightevoked change in consumption under normal conditions to be $\Delta Q_{\text {net }}$, and the $\mathrm{Na}^{+}$pump dependent and cGMP dependent changes to be $\Delta \mathrm{Q}_{\mathrm{Na} \text { pump }}$ and $\Delta \mathrm{Q}_{\mathrm{cGMP}}$, then, at a particular illumination,

$$
\Delta Q_{\text {net }}=\Delta Q_{\text {Na pump }}+\Delta Q_{\text {cGMP }}
$$

Values have been obtained for $\Delta Q_{\text {net }}$, but in low $\left[\mathrm{Na}^{+}\right]$ it was not possible to estimate the light-evoked difference in $\mathrm{QO}_{2}$ of the photoreceptors (Haugh-Scheidt et al., 1995). Therefore, a reliable estimate of $\Delta Q_{\mathrm{cGMP}}$ could not be obtained from that data. Another approach is to use the values of $\Delta \mathrm{PO}_{2}$ measured near the photoreceptors as a reflection of $\Delta \mathrm{Q}$. From the steady-state diffusion model presented in the accompanying paper, it can be shown that observed changes in $\Delta \mathrm{P}$ at the inner segment are linear with the underlying change in $\mathrm{QO}_{2}$ of the photoreceptors, i.e. $\Delta \mathrm{P}=k \Delta \mathrm{Q}$, so that eqn (6) becomes

or

$$
\begin{aligned}
& \frac{\Delta P_{\text {net }}}{k}=\frac{\Delta P_{\text {Na pump }}}{k}+\frac{\Delta P_{\text {cGMP }}}{k} \\
& \Delta P_{\text {Na pump }}=\Delta P_{\text {net }}-\Delta P_{\text {cGMP }}
\end{aligned}
$$

To examine the relative magnitudes of $\Delta P_{\mathrm{Napump}}$ and $\Delta P_{\mathrm{CGMP}}$, the derived values of $\Delta P_{\mathrm{Na} \text { pump }}$, obtained from the measured values of $\Delta P_{\text {net }}$ and $\Delta P_{\mathrm{cGMP}}$ were plotted as a function of $\Delta P_{\text {eqMP }}$ as shown in Fig. 8. The ratio of $\Delta P_{\mathrm{Na} \text { pump }}$ to $\Delta P_{\mathrm{CGMP}}$ should give an indication of the relative sizes of the pump dependent and cGMP dependent changes in oxidative metabolism during illumination. This ratio is not really constant, but has 
an average value of $3.58 \pm 1.39(n=48)$ (omitting points where $\Delta P_{\text {cGMP }}<5 \mathrm{mmHg}$ ). This result, which depends on both normal and low $\left[\mathrm{Na}^{+}\right]$responses, can be compared to another approximation of the same quantity, the inverse of the $P_{1} / P_{2}$ ratio given in the Results. That ratio, which depends only on fitting the time course of the normal $\left[\mathrm{Na}^{+}\right]$responses, is $2 \cdot 3$. Taken together, these suggest that the change in metabolic requirement for $\mathrm{Na}^{+}$pumping during illumination is in the range of $2 \cdot 3$ to 3.6 times as large as (and, of course, in the opposite direction to) the change in the metabolic requirement for cGMP synthesis during illumination. This pump/synthesis ratio is similar to the ratio of $3 \cdot 2(41 \% / 13 \%)$ that was observed in rabbit (Ames et al., 1992). It should be noted that this only provides information about changes with light. Further quantitative analysis of the total energy requirement of each process relies on knowing the absolute value of consumption for each process in the dark or light, which has not yet been obtained.

\section{Acknowledgements}

This research was supported by NEI grant EY05034 and University of Cincinnati Research Council.

\section{References}

Ames III, A., Ying-Ying, L., Heher, E. C. and Kimble, C. R. (1992). Energy metabolism of rabbit retina as related to function: high cost of $\mathrm{Na}^{+}$transport. J. Neurosci. 12 , 840-53.

Dawis, S. M., Graeff, R. M., Heyman, R. A., Walseth. T. F. and Goldberg. N. D. (1988). Regulation of cyclic GMP metabolism in toad photoreceptors. J. Biol. Chem. 263. 8771-85.

Dawis, S. M., Walseth. T. F., Deeg, M. A., Heyman, R. A., Graeff, R. M. and Goldberg. N. D. (1989). Adenosine triphosphate utilization rates and metabolic pool sizes in intact cells measured by transfer of ${ }^{18} \mathrm{O}$ from water. Biophys. J. 55, 79-99.

Fain, G. L. (1976). Sensitivity of toad rods: dependence on wave-length and background illumination. J. Physiol. (Lond.) 261, 71-101.
Gorczyca, W. A., Gray-Keller, M. P., Detwiler, P. B. and Palczewski, K. (1994). Purification and physiological evaluation of a guanylate cyclase activating protein from retinal rods. Proc. Natl. Acad. Sci., U.S.A. 91, 4014-18.

Haugh, L. M., Griff, E. R. and Linsenmeier, R. A. (1991). Light-evoked oxygen responses in the isolated toad retina. Invest. Ophthalmol. Vis. Sci. 32 (Suppl.), 671.

Haugh-Scheidt, L. M., Linsenmeier, R. A. and Griff, E. R. (1995). Oxygen consumpiion in the isolated toad retina. Exp. Eye Res. 61. 63-72.

Kimble, E. A., Svoboda, R. A. and Ostroy, S. E. (1980). Oxygen consumption and ATP changes of the vertebrate photoreceptor. Exp. Eye Res. 31, 271-88.

Koch, K.-W. and Stryer, L. (1988). Highly cooperative feedback control of retinal rod guanylate cyclase by calcium ions. Nature 334, 64-6.

Liebman, P. A. and Entine, G. (1968). Visual pigments of frog and tadpole (Rana pipiens). Vision Res. 8, 761-75.

Linsenmeier, R. A. (1986). Effects of light and darkness on oxygen distribution and consumption in the cat retina. J. Gen. Physiol. 88, 521-42.

Pepe. I. M., Boero, A., Vergani, L., Panfolli, I. and Cugnoli, C. (1986). Effect of light on cyclic GMP synthesis in rod outer segments of toad retina. Biochim. Biophys. Acta. $889,271-6$.

Poitry, S., Cornwall, C., Fein, A. and Tsacopoulos, M. (1993). Measurement of a light-induced change in $O_{2}$ consumption on a single rod photoreceptor. Invest. Ophthalmol. Vis. Sci. 34 (Suppl.). 1279.

Shimazaki, H. and Oakley, B. (1984). Reaccumulation of $\left[\mathrm{K}^{+}\right]_{0}$ in the toad retina during maintained illumination. J. Gen. Physiol. 84, 475-504.

Sickel, W. (1972). Retinal metabolism in dark and light. In Physiology of Photoreceptor Organs. Handbook of Sensory Physiology. Vol. II/2 (Ed. Fuortes, M. G. F.) Pp. 667-727. Springer-Verlag: Berlin.

Stefansson, E.. Wolbarsht, M. L. and Landers III, M. B. (1983). In vivo $\mathrm{O}_{2}$ consumption in rhesus monkey in light and dark. Exp. Eye Res. 37, 251-6.

Uga, S. and Smelser, G. K. (1973). Comparative study of the fine structure of retinal Müller cells in various vertebrates. Invest. Ophthalmol. 12, 434-48.

Woodruff, M. L., Fain. G. L. and Bastian. B. L. (1982). Lightdependent ion influx into toad photoreceptors. J. Gen. Physiol. 80, 517-36.

Zhang, Y. and Straznicky, C. (1991). The morphology and distribution of photoreceptors in the retina of $B u f o$ marinus. Anat. Embryol. 183, 97-104.

Zuckerman, R. and Weiter, J. J. (1980). Oxygen transport in the bullfrog retina. Exp. Eye 1 Res. 30, 117-27. 